nature

Volume 247

February 15, 1974

\section{Is it fair to force your baby to smoke cigarettes?}



This is what happens if you smoke when you're pregnant.

Every time you inhale you fill your lungs with nicotine and carbon monoxide.

Your blood carries these impurities through the umblical cord into your baby's bloodstream.

Smoking can restrict your baby's normal growth inside the womb.

It can make him underdeveloped and underweight at birth.

Which, in turn, can make him vulnerable to illness in the first delicate weeks of his life.

It can even kill him.

Last year, in Britain alone, over 1,500 babies might not have died if their mothers had given up smoking when they were pregnant.

If you give up smoking when you're pregnant your baby will be as healthy as if you'd never smoked.

\section{(2)}

The Health Education Council

\section{... or force your wife to feel guilty?}

WiтH the recent publication by the Health Education Council of the above poster, we return with some reluctance to the smoking and pregnancy issue, subject of the leader of September 14, 1973.

The results of a large study showed that non-smokers have, on average, heavier babies than do smokers, and, probably as a consequence, the pregnant mother who smokes has a $30 \%$ greater chance of losing her child than does the non-smoker. Furthermore those who voluntarily gave up smoking during pregnancy had 'nonsmoker' babies-heavicr and more likely to survive.

The question we raised then and we raise again now is that of the advice that scientists should give the public. It is a central question, and one which crops up in many guises whenever scientific work impinges on public policy making. The obvious first reaction is 'if it abates, do it immediately: discuss cause at leisure'. Dr Renwick has recently argued eloquently for greater emphasis on abatement in medical science (246, 114; 1973). There is, of course, still some residual scientific disagreement (as our correspondence showed) about whether it is the smoker or the smoking that leads to lighter babies, but surely with 1500 lives a year at stake the Health Education Council is justified in spending $£ 120,000$ abatively on a frontal (well, lateral) assault on the smoking mother-to-be?

Clearly, stopping smoking during pregnancy is a most desirable thing. If the campaign had been simply to encourage those for whom smoking is an optional activity to opt appropriately, one could have few quarrels with it. But the approach is more than suggestive. Words like 'force' and 'kill' arc intended to shock and the target is as much the hardened as the casual smoker. The back of the leaflet consists of a guide to stopping smoking that could have been culled from an army manual-from "there's no painless way to stop smoking, no wonder cure" through to "having made the decision to stop, you must stick firmly to that decision". Poor pregnant mother. As if she doesn't have enough kindly advice and isn't already under enough pressure without being instructed to give up what may have been a lifelong habit. If she succeeds, it won't (as they say) be painless. If she fails, the campaign will at least have instilled guilt, and if she fails and then loses her child, who is to explain to her that only one in four of such losses is attributable to smoking?

Half a million leaflets have been distributed to await the pregnant mother. This well-intentioned campaign would have been much more effective and humane if the money had been used on half a million somewhat less scaring leaflets for schoolgirls informing them that starting smoking now could lead to problems in pregnancy. The way to advise the pregnant mother is not through a stark leaflet but through a well-informed doctor or nurse who can assess what sort of approach is suitable for each individual-and possibly avoid words like 'kill'.

\section{0 years ago}



$W_{E}$ have received some interesting notes of the work done by the eminent Russian explorer, Dr, von Miclucho-Maclay, which we hope to publish next week. Contrary to the advice of every. one, this intrepid traveller and true devotee of Science is determined upon again visiting the east coast of Papua. When his researches here are complete he intends to visit some of the islands of Polynesia and certain parts of the coast of Australia. This, he calculates, will take up five or six years. The Governor of the Dutch East Indies, like a true man of Science, had given Dr. Maclay, for the last six months, roomy and comfortable quarters in his palace at Buitonrovg. It would be well if all in high position would imitate this kind of "patronage." 